\title{
PKM - PENGUSAHA ARANG TEMPURUNG KELAPA DESA BANTAN AIR KABUPATEN BENGKALIS
}

\author{
Abdul Haris Salam*1, Syahrizal ${ }^{2}$ \\ ${ }^{1,2}$ Politeknik Negeri Bengkalis; Jl. Bathin Alam-Sungai Alam, Telp/Fax: +62 (766) 24566 \\ *E-mail: abdulharissalam@polbeng.ac.id
}

\begin{abstract}
Bantan Air Village, which is part of Bantan District, Bengkalis Regency, has been established by two SMEs and is engaged in processing coconut shells into charcoal. Both of these MSMEs already have burning stoves but have the same problem, namely the smoke produced from burning coconut shells is released into the air without further treatment. The smoke that is discharged can of course disrupt the health of workers or the community around the place of business. Thus, it is necessary to apply more applicable science and technology to reduce smoke pollution and even convert the smoke waste into something that has a selling value. The proposer and the two partners have agreed to solve this problem, namely the manufacture of condensers to turn smoke into liquid, so that the aim of reducing pollution and increasing revenue can be achieved. This PKM activity begins with a preliminary survey to the location of partners and determines the solution to the problem, followed by the making of a condenser, provides training in how to operate equipment, care and guidance. The output target of this PKM has been achieved by producing a condenser to reduce smoke from the burning of coconut shells and produce products in the form of liquid smoke that is ready to sell. In addition, the community and MSME workers have also been given counseling and training in the use of condensers so that the knowledge and skills of workers can increase
\end{abstract}

Keywords-Condenser, liquid smoke, coconut shell

\begin{abstract}
Abstrak
Desa Bantan Air yang merupakan bagian dari kecamatan Bantan kabupaten Bengkalis telah berdiri dua UMKM dan bergerak pada bidang pengolahan tempurung kelapa menjadi arang. Kedua UMKM ini sudah memiliki tungku pembakaran namun mempunyai masalah yang sama yaitu asap yang dihasilkan dari pembakaran tempurung kelapa dilepas begitu saja ke udara tanpa ada perlakuan lanjut. Asap yang dibuang tersebut tentu saja dapat mengganggu kesehatan pekerja ataupun masyarakat yang ada disekitar tempat usaha. Dengan demikian diperlukan penerapan IPTEK yang lebih mempuni untuk mengurangi pencemaran asap dan bahkan mengubah limbah asap tersebut menjadi sesuatu yang memiliki nilai jual. Pengusul dan kedua mitra telah sepakat untuk solusi masalah ini yaitu pembuatan kondensor untuk mengubah asap menjadi cair, agar tujuan untuk mengurangi pencemaran dan meningkatkan pendapatan bisa tercapai. Kegiatan PKM ini dimulai dengan survey awal ke lokasi mitra dan menentukan solusi dari permasalahan, dilanjutkan dengan pembuatan kondensor, memberikan pelatihan cara operasi alat, perawatan dan pembimbingan. Target luaran dari PKM ini telah tercapai dengan dihasilkannya kondensor untuk mengurangi asap hasil pembakaran tempurung kelapa dan menghasilkan produk berupa asap cair yang siap jual. Selain itu masyarakat dan pekerja UMKM juga telah diberikan penyuluhan dan pelatihan penggunaan kondensor tersebut sehingga pengetahuan dan keterampilan pekerja bisa bertambah
\end{abstract}

Kata kunci-Kondensor, asap cair, tempurung kelapa

\section{PENDAHULUAN}

Bengkalis adalah salah satu kabupaten penghasil buah kelapa terbesar di Provinsi Riau, berdasarkan data BPS Provinsi Riau tahun 2013 ada sekitar 12.684 Ha luas kebun kelapa di 
kabupaten Bengkalis. Melimpahnya ketersediaan buah kelapa ini menjadi penyokong utama berdirinya usaha mikro kecil menengah (UMKM) pengolahan buah kelapa, sehingga para pengusaha ini tidak perlu khawatir akan kekurangan bahan baku.

Menurut pemaparan pemilik UMKM desa bantan masalah utama yang mereka hadapi adalah banyaknya asap yang dihasilkan saat proses pembakaran tempurung kelapa. Asap yang keluar dari ruang pembakaran tersebut membuat iritasi mata dan terganggunya sistem pernapasan.

Solusi yang tepat untuk mengatasi permasalahan di mitra kegiatan PKM adalah dengan membuat alat yang dapat mengkonversi asap menjadi cair yang disebut sebagai kondensor. Hal yang ingin dijawab lewat kegiatan PKM ini adalah, sejauh mana alat tersebut nantinya dapat diterapkan dan memberikan solusi kepada pelaku usaha arang tempurung kelapa yang ada di Kabupaten Bengkalis. Hal ini sekaligus menjadi luaran yang ingin dicapai, yaitu sebuah teknologi tepat guna bagi pelaku usaha.

\section{METODE}

Metode pendekatan yang ditawarkan untuk menyelesaikan persoalan mitra yang telah disepakati bersama untuk permasalahan kesehatan lingkungan dan pendapatan dalam kurun waktu realisasi program PKM adalah:

1. Dari hasil survey dan observasi tim pengusul kegiatan PKM di tempat mitra sehingga permasalahan telah teridentifikasi maka disepakati permasalahan yang menjadi prioritas yaitu permasalahan pada bidang pendapatan dan kesehatan lingkungan.

2. Tim pengusul kegiatan PKM membuat alat yang dapat mengkonversi asap hasil pembakaran ke bentuk cairan di Workshop Jurusan Teknik Mesin Politeknik Negeri Bengkalis.

3. Penyerahan dan pengaplikasian alat konversi asap ke bentuk cair (kondensor) di mitra kegiatan PKM.

4. Tim pengusul kegiatan PKM mengadakan kegiatan pelatihan singkat cara pengoperasian serta cara perawatan alat konversi asap ke bentuk cair (kondensor).

5. Tim pengusul kegiatan PKM melakukan pendampingan untuk menjamin keberlangsungan program PKM yang telah diterapkan di mitra kegiatan.

Partisipasi mitra dalam pelaksanaan program kegiatan PKM pada usaha arang tempurung kelapa di Kecamatan Bantan ditunjukkan pada Tabel 1

Tabel 1 Partisipasi Mitra Dalam Pelaksanaan PKM

\begin{tabular}{|c|l|l|}
\hline No & \multicolumn{1}{|c|}{ Tujuan } & \multicolumn{1}{|c|}{ Partisipasi Mitra } \\
\hline 1 & Survey dan Observasi & $\begin{array}{l}\text { Menyediakan waktu untuk di survey dan } \\
\text { observasi }\end{array}$ \\
\hline 2 & $\begin{array}{l}\text { Mengenalkan teknologi pengubah asap } \\
\text { hasil pembakaran menjadi cairan }\end{array}$ & $\begin{array}{l}\text { Bersedia mendengarkan penjelasan mengenai } \\
\text { teknologi pengubah asap menjadi cair }\end{array}$ \\
\hline 3 & $\begin{array}{l}\text { Kesediaan mitra untuk bekerjasama dalam } \\
\text { program kegiatan PKM }\end{array}$ & $\begin{array}{l}\text { Bersedia menandatangani surat pernyataan } \\
\text { kerjasama dengan tim pengusul kegiatan PKM }\end{array}$ \\
\hline 4 & $\begin{array}{l}\text { Aplikasi dan pelatihan singkat cara } \\
\text { pengoperasian serta cara perawatan alat } \\
\text { pengubah asap menjadi cair (kondensor) }\end{array}$ & $\begin{array}{l}\text { Menyediakan tempat, bahan baku dan praktek } \\
\text { untuk mengikuti pelatihan }\end{array}$ \\
\hline 5 & $\begin{array}{l}\text { Pendampingan untuk menjamin } \\
\text { keberlangsungan program PKM }\end{array}$ & $\begin{array}{l}\text { Bersedia dikunjungi oleh tim pengusul } \\
\text { kegiatan PKM }\end{array}$ \\
\hline
\end{tabular}

Dalam mengukur tingkat keberhasilan kegiatan PKM maka tim pengusul kegiatan PKM melakukan evaluasi pelaksanaan program dan keberlanjutan program setelah selesai dilaksanakan dengan melibatkan LPPM Politeknik Negeri Bengkalis yang ditunjukkan pada Tabel 2 
DINAMISIA - Jurnal Pengabdian Kepada Masyarakat $\quad$ Vol. 2, No.2 Desember 2018, Hal. 278-282

Tabel 2 Kriteria dan Indikator Evaluasi Pelaksanaan Program dan Keberlanjutan Program

\begin{tabular}{|c|c|c|c|}
\hline No & Item & Indikator & Kriteria Keberhasilan \\
\hline 1 & $\begin{array}{l}\text { Penggunaan alat } \\
\text { konversi asap menjadi } \\
\text { cair (kondensor) di } \\
\text { mitra kegiatan PKM }\end{array}$ & $\begin{array}{l}\text { Dihasilkannya asap cair dari } \\
\text { alat konversi asap ke cair } \\
\text { (kondensor) }\end{array}$ & $\begin{array}{l}\text { Asap yang dihasilkan dari } \\
\text { pembakaran berkurang sehingga } \\
\text { tidak mengganggu pekerja dan } \\
\text { masyarakat sekitar. }\end{array}$ \\
\hline 2 & $\begin{array}{l}\text { Pelatiahan singkat } \\
\text { cara pengoperasian } \\
\text { serta cara perawatan } \\
\text { alat konversi asap ke } \\
\text { cair (kondensor) }\end{array}$ & $\begin{array}{l}\text { Ketrampilan mitra } \\
\text { mengoperasikan dan merawat } \\
\text { alat konversi asap ke cair } \\
\text { (kondensor) }\end{array}$ & $\begin{array}{l}\text { Mitra kegiatan PKM sudah } \\
\text { mampu mengoperasikan, } \\
\text { merawat alat konversi asap ke cair } \\
\text { (kondensor) }\end{array}$ \\
\hline 3 & $\begin{array}{l}\text { Pendampingan dan } \\
\text { monitoring }\end{array}$ & $\begin{array}{l}\text { Tim pengusul kegiatan PKM } \\
\text { melakukan pendampingan } \\
\text { dan monitoring secara berkala }\end{array}$ & $\begin{array}{l}\text { Alat konversi asap ke cair } \\
\text { (kondensor) masih digunakan dan } \\
\text { dirawat sesuai dengan arahan } \\
\text { yang telah diberikan. }\end{array}$ \\
\hline
\end{tabular}

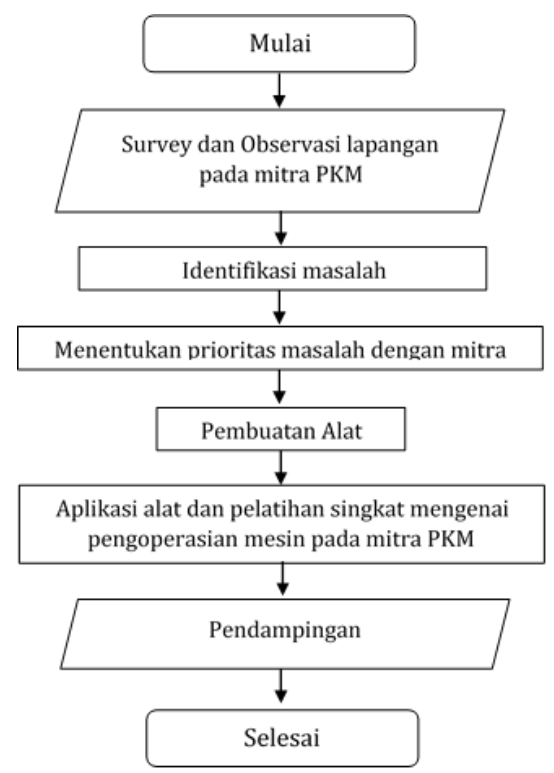

Gambar. 1 Flowchart pelaksanaan kegiatan PKM

\section{HASIL DAN PEMBAHASAN}

Adapun hasil dan luaran yang dihasilkan dari kegiatan PKM ini adalah sebagai berikut:

\section{Kondensor Asap Cair Model Tanki dan Pipa Spiral}

Kondensor adalah alat yang digunakan untuk mengkondensasi uap atau asap hasil pembakaran sehingga burubah bentuk dari gas menjadi cair akibat penurunan temperatur, kemudian cairan yang dihasilkan disebut sebagai asap cair.

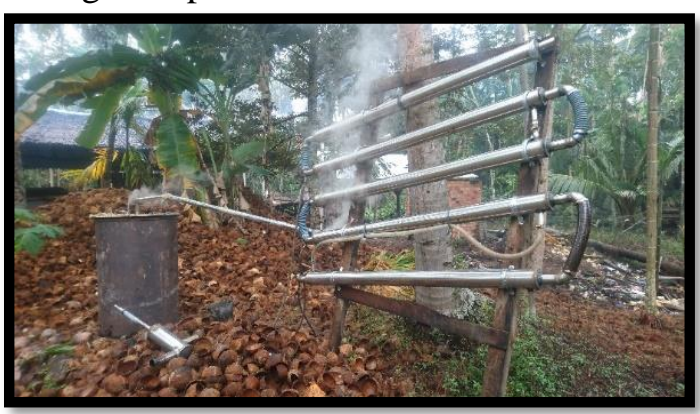

Gambar 2 Kondensor tabung paralel 


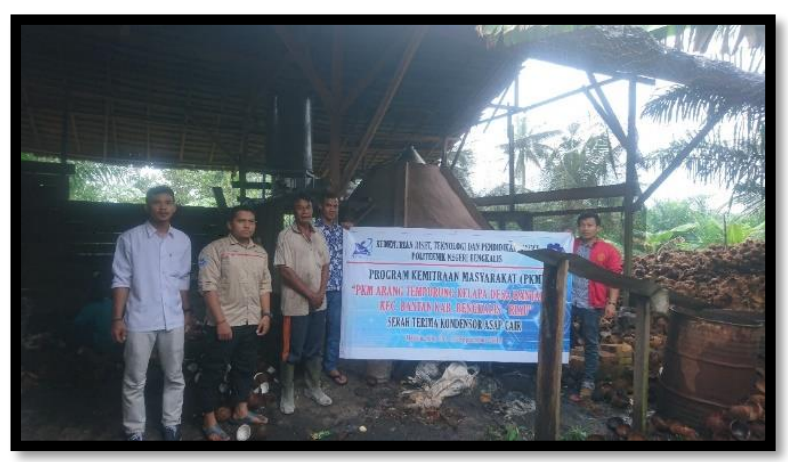

Gambar 3 Kondensor tanki

2. Asap cair hasil kondensor

Asap cair adalah produk yang dihasilkan oleh kondensor. Asap cair terdiri dari beberapa grade yaitu grade 1 , grade 2 dan grade 3 . Asap cair dapat dimanfaatkan sebagai bahan pengawet alami serta pestisida alami.

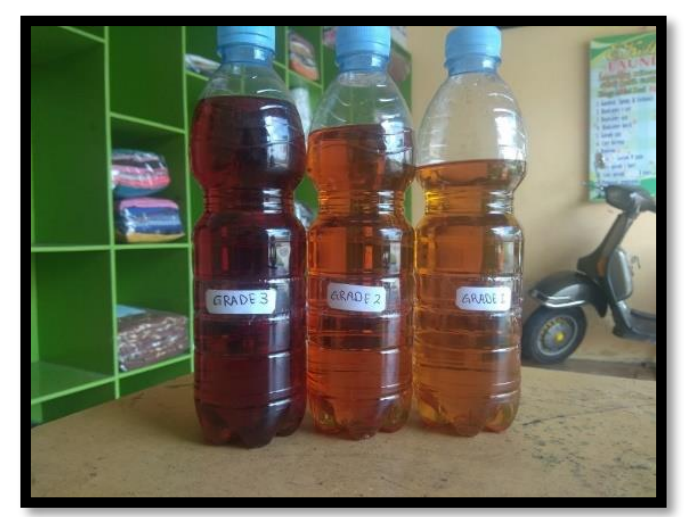

Gambar 4 Asap cair hasil kondensasi

\section{Kegiatan penyluhan dan Pelatihan}

Penyuluhan dan pelatihan diberikan kepada masyarakat sekitar UMKM dan pekerja UMKM dengan tujuan untuk memperkaya pengetahuan tentang kelapa dan peralatan yang dapat dugunakan untuk pengolahannya.

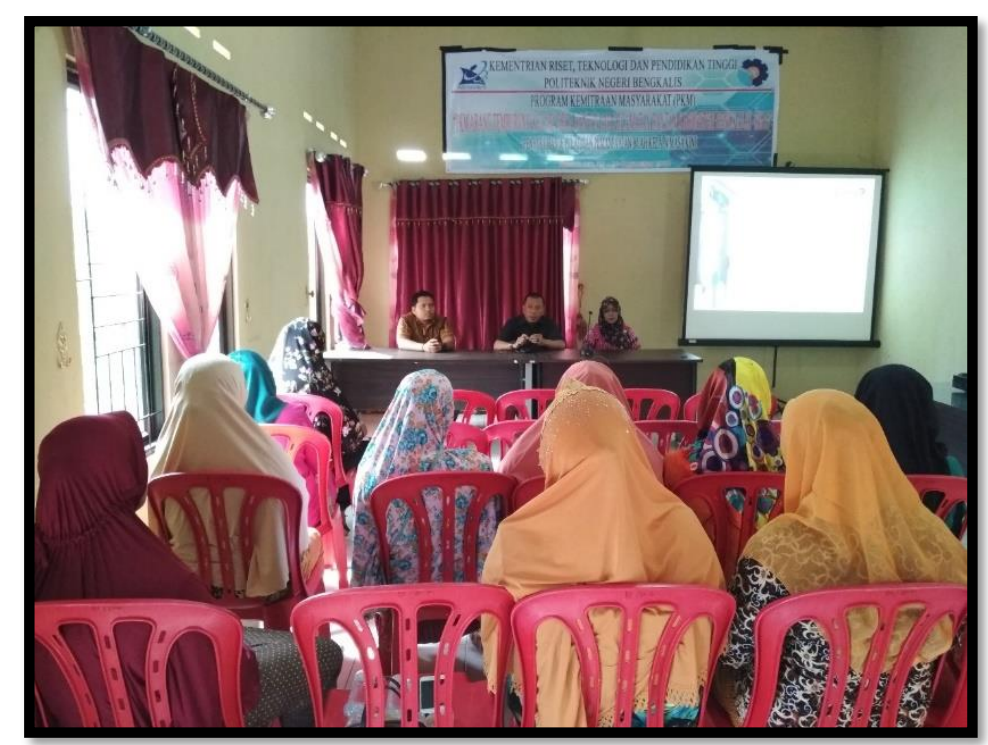

Gambar 5 Potret kegiatan penyuluhan dan pelatihan 


\section{KESIMPULAN}

Kegiatan PKM telah dilakukan dengan baik, mulai dari survey awal untuk menentukan masalah mitra dan solusinya, kemudian dilanjutkan dengan pembuatan dua buah kondensor yaitu kondensor model tabung paralel dan kondensor model tanki telah selesai. Serah terima peralatan kondensor juga telah dilakukan yang disertai dengan pemberian penyluhan dan pelatihan untuk meningkatkan pengetahuan dan keterampilan perkerja dan masyarakat yang ada disekitar mitra PKM

\section{SARAN}

Pengabdian yang selanjutnya disarankan agar produksi asap cair dapat dipasarkan dan mempunyai lebel sendiri yang mencerminkan indentitas daerah tersebut sehingga dapt memajukan dan meningkatkan kualitas ekoomi dan daya saing desa.

\section{UCAPAN TERIMA KASIH}

Penulis mengucapkan terima kasih kepada Kemenristekdikti yang telah mendanai program kemitraan masyarakat ini sehingga dapat berjalan dengan sukses. Terimakasih juga kepada pihakpihak yang telah ikut serta dalam kegitan pengabdian ini baik dari civitas akademika Politeknik Negeri Bengkalis dan perangkat desa Bantan Air dan Bantan Sari.

\section{DAFTAR PUSTAKA}

[1] Fachraniah, dkk. (2009). Peningkatan Kualitas Asap Cair Dengan Distilasi. Jurnal Teknik Kimia POLNELHO, Vol.7, No.14

[2] Ginayati L, dkk. (2015). Pemanfaatan Asap Cair Dari Pirolisis Cangkang Kelapa Sawit Sebagai Pengawet Alami Tahu. Jurnal Teknik Kimia USU, Vol.4, No.3

[3] Noor E, dkk.(2010). Isolasi Pemurnian Asap Cair Berbahan Dasar Tempurung dan Sabut Kelapa Secara Pirolisis dan Distilasi

[4] Prasetiowati, dkk. (2014). Pembuatan Asap Cair Dari Cangkang Buah Karet Sebagai Koagulan Lateks. Jurnal Teknik Kimia No. 4, Vol.20, Hal. 14-21

[5] Yunus M. (2011). Teknologi Pembuatan Asap Cair Dari Tempurung Kelapa Sebagai Pengawet Makanan. Jurnal Sains dan Inovasi Vol 7. No 1. Hal 53-61Castleman, Kenneth R., 2004, Digital Image Processing, Vol. 1, Ed.2, Prentice Hall, New Jersey. 